\title{
Does total-factor productivity drive housing prices? A growth-accounting exercise for four countries
}

\author{
Alessio Moro ${ }^{\mathrm{a}, *}$, Galo Nuño ${ }^{\mathrm{b}}$ \\ a Department of Economics, Universitá di Cagliari, Viale Sant'Ignazio 17, 09123, Cagliari, Italy \\ ${ }^{\mathrm{b}}$ Banco de España, Alcalá 48, 28014, Madrid, Spain
}

\section{A R T I C L E I N F O}

\section{Article history:}

Received 16 September 2010

Received in revised form

22 November 2011

Accepted 13 December 2011

Available online 21 December 2011

\section{JEL classification:}

E01

E23

E25

E32

Keywords:

Housing prices

TFP

Growth accounting

Cobb-Douglas assumption

\begin{abstract}
A B S T R A C T
Housing prices diverge from construction prices after 1997 in four major countries. Besides, total-factor productivity (TFP) differences between construction and the general economy account for the evolution of construction prices in the US and Germany, but not in the UK and Spain.
\end{abstract}

(C) 2011 Elsevier B.V. All rights reserved.

\section{Introduction}

We investigate the role of differences in total-factor productivity (TFP) growth between the construction sector and the general economy in the evolution of real housing prices in four major countries. We first compare housing prices with construction prices in the US, the UK, Spain, and Germany. The first three countries experienced major housing price booms in the first decade of the 21st century, whereas housing prices in Germany have been roughly stable. We find that housing prices closely follow construction prices during the pre-1997 period while they diverge afterwards in all countries, although to a different extent. Only in the US were the two prices back to a common level in 2007.

Secondly, we use a growth-accounting framework (Solow, 1957; Jorgenson et al., 1987) and its dual approach (Oulton,

\footnotetext{
We thank Henrique Basso, Joel Lopez-Real, Paolo Mattana, Anton Nakov, seminar participants at the Bank of Spain, and an anonymous referee for the useful comments. The views expressed are those of the authors and do not necessarily represent the views of the Bank of Spain or the Eurosystem.

* Corresponding author. Tel.: +39070 6753341 .

E-mail addresses: amoro@unica.it (A. Moro), galo.nuno@bde.es (G. Nuño).
}

2007) to assess the contribution of the TFP growth differential between the construction sector and the general economy on construction prices. $^{1}$ If the TFP grows more slowly in the construction sector than in the overall economy, then the relative price of construction goes up as a particular case of Baumol's "cost disease" (Baumol, 1967). Our results suggest that the surge in construction prices in the US is the consequence of an increase in relative TFP growth between the general economy and the construction sector, especially since the mid-1990s. ${ }^{2}$ Relative TFP also drives construction prices in Germany. However, we find that the rise in construction prices in both the UK and Spain is not due to TFP differences but to relative rental prices of labor and capital between the construction sector and the general economy.

\footnotetext{
1 In contrast with standard growth accounting that requires quantity indices to be implemented, the dual growth-accounting framework requires the use of price indices. Oulton (2007) uses this approach to compute the relative price of equipment to consumption. See also Hsieh (2002).

2 Iacoviello and Neri (2010) and Kahn (2008) find a similar result in the context of dynamic general equilibrium models. For the acceleration of aggregate TFP in the US, see Jorgenson and Stiroh (2000).
} 

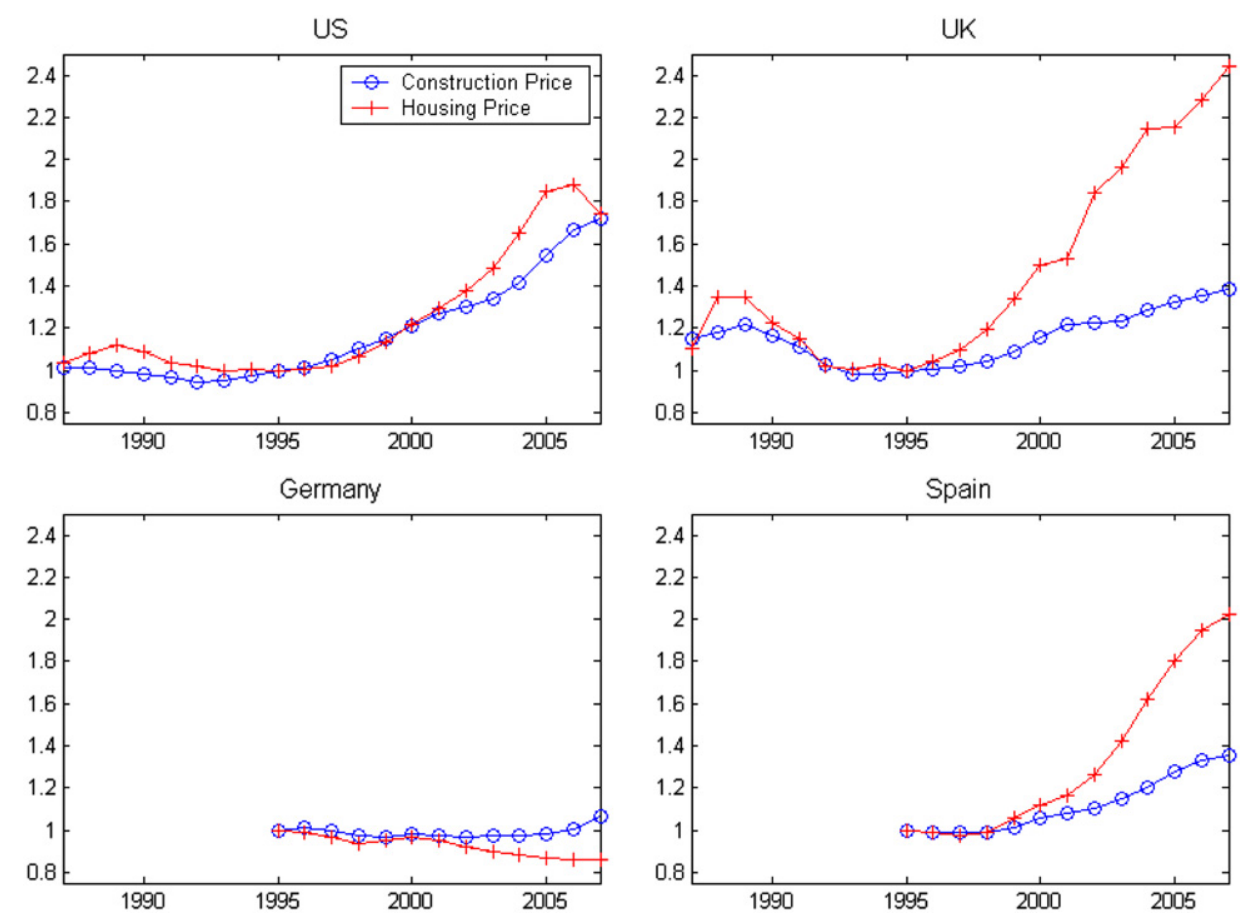

Fig. 1. Price of Construction and Housing Price Index. Both indices are divided by the GDP deflator and normalized to one in 1995.

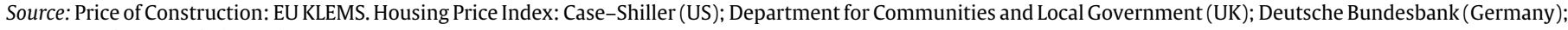
Ministerio de Vivienda (Spain).

\section{Housing prices versus construction prices}

Fig. 1 displays construction and housing prices for the US, the UK, Germany, and Spain from 1987 to 2007.3 In the US, the housing prices track the construction prices until 2001. During the "housing boom", from 2002 to 2006, house prices rise more quickly than construction prices. In 2007, housing prices fall to the same level as construction prices. Overall, construction prices have grown by around $70 \%$ since 1987 , a magnitude similar to the increase in housing prices. In the UK and in Spain, instead, house prices more than doubled in the decade 1997-2007 whereas construction prices only grew by around $40 \%$. In Germany, house prices fell by more than $10 \%$ after 2003 whereas construction prices grew slightly. Thus, construction prices seem to play a pivotal role in the evolution of house prices in the US, whereas the relationship between both prices is feebler in the other countries.

\section{Growth-accounting methodology}

We assume that the production in the construction sector $c$ and in the general economy $g$ at time $t, Y_{i, t}$, follows a Cobb-Douglas function:

$Y_{i, t}=A_{i, t} K_{i, t}^{\alpha_{i}} L_{i, t}^{1-\alpha_{i}}, \quad i=\{c, g\}$,

where $K_{i, t}$ and $L_{i, t}$ are, respectively, the sector-wide capital and labor services and $A_{i, t}$ is the total-factor productivity (TFP). Capital and labor services in the two sectors are not required to be homogenous. Given (1), the TFP can be computed using data on sectoral output, capital services, and labor services.

With competitive markets, the price of one unit of $Y_{i, t}$ is, in equilibrium,

$P_{i, t}=\frac{W_{i, t}^{1-\alpha_{i}} R_{i, t}^{\alpha_{i}}}{\alpha_{i}^{\alpha_{i}}\left(1-\alpha_{i}\right)^{1-\alpha_{i}}} \frac{1}{A_{i, t}}$, where $R_{i, t}$ is the rental rate of capital and $W_{i, t}$ is the wage rate in sector $i$. Eq. (2) implies that

$$
\begin{gathered}
\frac{\left(P_{c, t} / P_{g, t}\right)}{\left(P_{c, t} / P_{g, t}\right)}=\underbrace{\alpha_{c} \frac{\dot{R}_{c, t}}{R_{c, t}}-\alpha_{g} \frac{\dot{R}_{g, t}}{R_{g, t}}+\left(1-\alpha_{c}\right) \frac{\dot{W}_{c, t}}{W_{c, t}}-\left(1-\alpha_{g}\right) \frac{\dot{W}_{g, t}}{W_{g, t}}}_{(a)} \\
+\underbrace{\frac{\left(A_{g, t} / A_{c, t}\right)}{\left(A_{g, t} / A_{c, t}\right)}}_{(b)} .
\end{gathered}
$$

Eq. (3) allows us to decompose the growth in the relative price of construction into two components: one $(a)$ that depends on the growth in the price of capital and labor services in the two sectors weighted by the intensity of capital and labor services in production, determined by $\alpha_{c}$ and $\alpha_{g}$; and the second $(b)$ that depends on the TFP growth differential between the two sectors. By using (3), it is possible to separate the increase in the relative price of construction due to market conditions (changes in the prices of capital and labor) from that due to different TFP growth in the two sectors.

\section{Results}

If the Cobb-Douglas function is a good approximation of the production technology, the price of output measured in the data should be close to the theoretical price given by (2), and (3) can be used to decompose the relative price of construction. To test whether the Cobb-Douglas assumption is supported by the data, we first compute the TFP $A_{i, t}$ in construction and in the general economy using data for $Y_{i, t}, K_{i, t}, L_{i, t}$ and (1). Data are from the EU KLEMS database. ${ }^{4}$ Next, by taking logarithms of (2), we obtain

$$
\log \left(P_{i, t}\right)=\beta_{i}+\beta_{i, r} \log \left(R_{i, t}\right)+\beta_{i, w} \log \left(W_{i, t}\right)+\beta_{i, a} \log \left(A_{i, t}\right),
$$

\footnotetext{
3 The Appendix provides a description of the data.
}

\footnotetext{
4 See the Appendix for details.
} 
Table 1

Cobb-Douglas test.

\begin{tabular}{lllllllll}
\hline Construction & US & \multicolumn{2}{c}{ UK } & \multicolumn{3}{c}{ Germany } & \multicolumn{2}{c}{ Spain } \\
\hline$\alpha_{c}$ & 0.10 & & 0.15 & & 0.18 & & 0.27 \\
\hline$\beta_{c}$ & -0.01 & $(0.01)$ & 0.02 & $(0.01)$ & -0.00 & $(0.00)$ & 0.00 & $(0.00)$ \\
$\beta_{c, r}$ & $0.07^{* * *}$ & $(0.01)$ & $0.14^{* * *}$ & $(0.01)$ & $0.18^{* * *}$ & $(0.00)$ & $0.28^{* * *}$ & $(0.00)$ \\
$\beta_{c, w}$ & $0.93^{* * *}$ & $(0.02)$ & $0.84^{* * *}$ & $(0.01)$ & $0.82^{* * *}$ & $(0.00)$ & $0.72^{* * *}$ & $(0.00)$ \\
$\beta_{c, A}$ & $-1.02^{* * *}$ & $(0.04)$ & $-0.91^{* * *}$ & $(0.05)$ & $-1.04^{* * *}$ & $(0.02)$ & $-1.02^{* * *}$ & $(0.01)$ \\
$F_{c}$ & 0.02 & & $6.15^{* *}$ & & 0.30 & & 2.70 & \\
\hline Whole economy & US & & UK & & Germany & \multicolumn{3}{c}{ Spain } \\
\hline$\alpha_{g}$ & 0.35 & & 0.28 & & 0.31 & & 0.37 & \\
\hline$\beta_{g}$ & 0.00 & $(0.00)$ & 0.00 & $(0.00)$ & $0.00^{* * *}$ & $(0.00)$ & -0.00 & $(0.00)$ \\
$\beta_{g, r}$ & $0.35^{* * *}$ & $(0.00)$ & $0.28^{* * *}$ & $(0.00)$ & $0.30^{* * *}$ & $(0.00)$ & $0.37^{* * *}$ & $(0.00)$ \\
$\beta_{g, w}$ & $0.65^{* * *}$ & $(0.00)$ & $0.72^{* * *}$ & $(0.00)$ & $0.67^{* * *}$ & $(0.01)$ & $0.64^{* * *}$ & $(0.00)$ \\
$\beta_{g, A}$ & $-1.00^{* * *}$ & $(0.00)$ & $-1.02^{* * *}$ & $(0.00)$ & $-0.92^{* * *}$ & $(0.02)$ & $-1.01^{* * *}$ & $(0.00)$ \\
$F_{g}$ & 0.51 & & $3.56^{*}$ & & $22.07^{* * *}$ & & $5.51^{* *}$ & \\
\hline
\end{tabular}

Standard errors are in brackets, $\alpha$ is the time average capital share in GDP, and $F$ is the value of the $F$-test for constant returns to scale in production.

***,** and ${ }^{*}$ denote, respectively, $1 \%, 5 \%$ and $10 \%$ significance levels.

where $\beta_{i}=-\log \left[\alpha_{i}^{\alpha_{i}}\left(1-\alpha_{i}\right)^{1-\alpha_{i}}\right], \beta_{i, r}=\alpha_{i}, \beta_{i, w}=1-$ $\alpha_{i}$, and $\beta_{i, a}=-1$. Eq. (4) can be estimated by using data on $P_{i, t}, W_{i, t}, R_{i, t}$, and the series of $A_{i, t}$. If the estimated coefficients are statistically significant and close to their theoretical counterparts, then the Cobb-Douglas function represents a good approximation of the production technology. This is true because series $Y_{i, t}, K_{i, t}, L_{i, t}, P_{i, t}, W_{i, t}, R_{i, t}$ in the EU KLEMS database are not constructed subject to the Cobb-Douglas assumption.

Table 1 reports the results of estimates of the unrestricted regressions based on (4) for both construction and the general economy. ${ }^{5}$ All estimated coefficients are close to their theoretical values and statistically significant. ${ }^{6}$ We also run an $F$-test for constant returns to scale in production and find that the null hypothesis cannot be rejected at $1 \%$ significance level in all estimations apart from the German general economy. Fig. 2 reports the relative price of construction measured in the data (solid blue line) and the theoretical one (circle blue line) constructed using EU KLEMS data and the right-hand side of (2). The two series almost perfectly overlap in the graph for all countries.

Finally, we use (3) to decompose the growth in the relative price of construction. The results appear in Table $2 .^{7}$ For each country, the first three rows report the average yearly growth rate of the relative price $P_{C} / P_{G}$, of relative TFP $A_{G} / A_{C}$, and of relative rentals $\left(R_{C}^{\alpha_{C}} W_{C}^{1-\alpha_{C}}\right) /\left(R_{G}^{\alpha_{G}} W_{G}^{1-\alpha_{G}}\right)$, while the fourth and the fifth rows report the contribution of relative TFP and relative rentals to the growth of $P_{C} / P_{G}{ }^{8}$

In the US, $95 \%$ of the increase in the relative price of construction during the period 1980-2007 is explained by the increase in relative TFP. In particular, the acceleration of TFP growth in the general economy occurred in the 1990s is responsible for the steep increase in relative TFP measured in the last part of the sample. In the UK, however, changes in relative TFP contribute negatively to the relative price of construction, which increased

\footnotetext{
5 Eq. (2) implies a stable relationship among the variables $P_{i, t}, W_{i, t}, R_{i, t}$, and $A_{i, t}$. This implies that the corresponding time series in the data should be cointegrated. Although we do not perform a complete cointegration analysis, we test the stationarity of the residual series of each regression using the augmented Dickey-Fuller test. The residual series are stationary in each regression.

6 We also run the regressions by imposing the restrictions $\beta_{i, r}+\beta_{i, w}=1$ and $\beta_{i, a}=-1$. The estimated coefficients are very close to those obtained in the unrestricted regression.

7 We perform the decomposition experiment for the period in which data are available for the four countries, 1980-2007.

8 The sum of contributions might not sum to $100 \%$ due to large growth rates.
}

Table 2

Relative price growth decomposition, 1980-2007.

\begin{tabular}{llrcl}
\hline$\%$ & US & \multicolumn{1}{c}{ UK } & Germany & Spain \\
\hline Relative price & 2.37 & 0.56 & 0.93 & 0.97 \\
Relative TFP & 2.26 & -0.41 & 1.17 & 0.03 \\
Relative rentals & 0.11 & 0.98 & -0.23 & 0.94 \\
Contribution to price growth & & & & \\
$\quad$ Relative TFP & 95 & -73 & 125 & 3 \\
$\quad$ Relative rentals & 5 & 174 & -24 & 97 \\
\hline
\end{tabular}

Relative price $\frac{P_{C}}{P_{G}}$ relative TFP $\frac{A_{G}}{A_{C}}$ and relative rentals $\frac{R_{C}^{\alpha} C}{{ }_{C}^{\alpha} W_{C}^{1-\alpha_{C}}} \frac{R_{G}^{\alpha_{G}} W_{G}^{1-\alpha_{G}}}{\text { are average annual }}$ growth rates. All numbers are in percentages.

due to the rise in relative rentals. The case of Germany is similar to that of the US. The relative TFP growth is equal to $125 \%$ of the growth in the relative price of construction. Finally, in Spain, the relative TFP is not responsible for the increase in the relative price of construction during the period 1980-2007. To conclude, Fig. 2 reports the relative TFP and relative rentals in all countries.

\section{Conclusions}

We have shown that technological differences between the general economy and the construction sector can account for the evolution of housing prices in the US. In the UK and Spain, however, the evolution of construction prices and technological factors accounts for a small part of the surge in housing prices in the last decade. We conclude that, although the timing of the steep increase in housing prices is similar in all countries, the driving forces of this surge are different across countries.

\section{Appendix. Data appendix}

The EU KLEMS database, November 2009, provides the $Y_{i, t}, K_{i, t}, L_{i, t}, P_{i, t}, W_{i, t}, R_{i, t}$ indices for the construction sector and the general economy for the US, the UK, Germany, and Spain. The data coverage periods are 1970-2007 for the UK and Germany, 1977-2007 for the US, and 1980-2007 for Spain. Sources of the Housing Price Index are the Case-Shiller index for the US (available since 1987), the Department for Communities and Local Government for the UK (available since 1969), Deutsche Bundesbank for Germany (available since 1995) and Ministerio de Vivienda for Spain (available since 1995). To construct Fig. 1, we use data on housing prices and construction prices from 1987 (which is the first year for which the Case-Shiller index is available) for the US and 

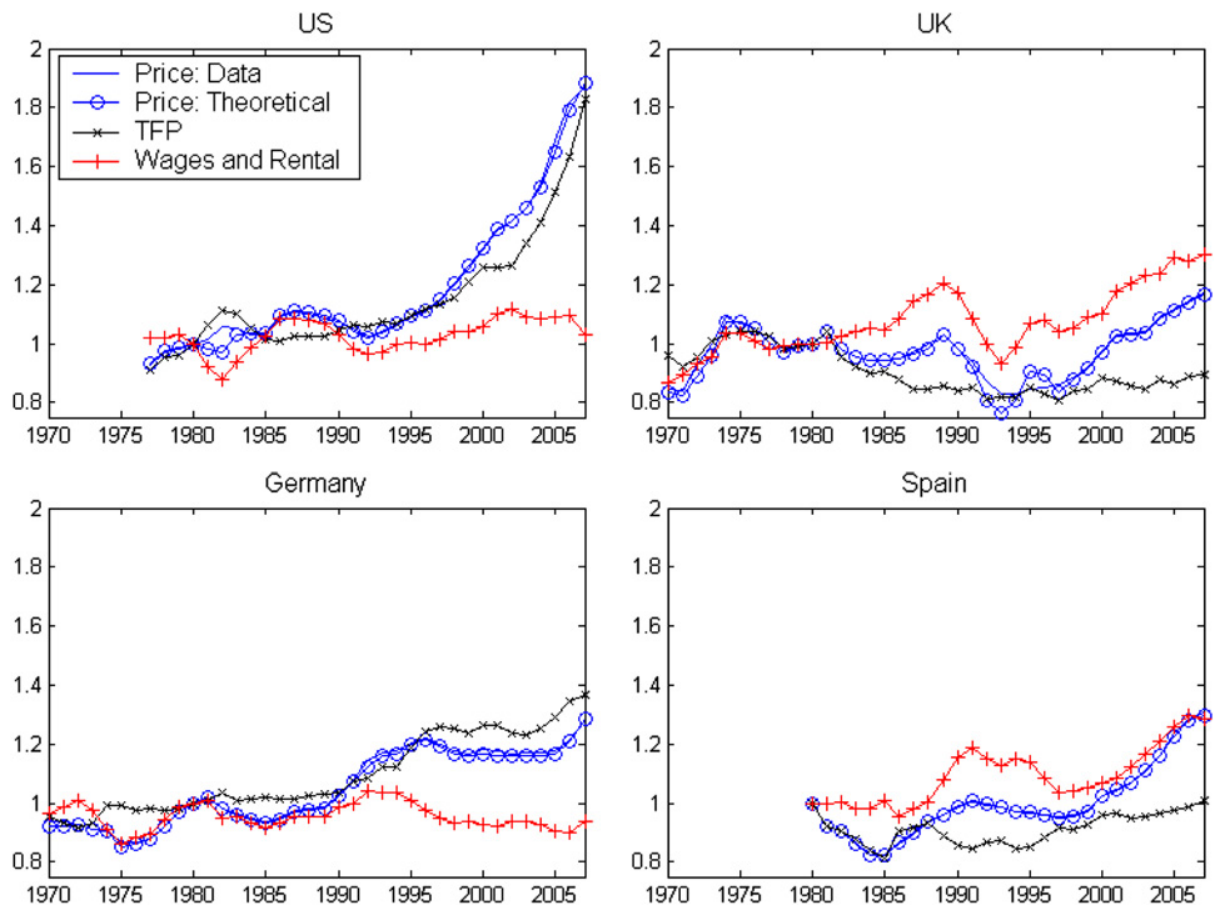

Fig. 2. Relative price of construction $P_{C} / P_{G}$, relative TFP $A_{G} / A_{C}$, and relative rentals $\left(R_{C}^{\alpha_{C}} W_{C}^{1-\alpha_{C}} / R_{G}^{\alpha_{G}} W_{G}^{1-\alpha_{G}}\right)(1980=1$ for all series).

Source: EU KLEMS and own computations.

the UK. ${ }^{9}$ For Germany and Spain, the first year for which both series are available is 1995. To obtain the results in Table 1 and to construct Fig. 2 we use, for each country, the maximum time span covered in the EU KLEMS database. Finally, in the decomposition experiment in Table 2, we use the longest period for which data are available for the four countries, which is 1980-2007.

\section{References}

Baumol, W., 1967. Macroeconomics of unbalanced growth: the anatomy of urban crisis. American Economic Review 57 (3), 415-426.
Hsieh, C., 2002. What explains the industrial revolution in east Asia? evidence from the factor markets. American Economic Review 92 (3), 502-526.

Iacoviello, M., Neri, S., 2010. Housing market spillovers: Evidence from an estimated DSGE model. American Economic Journal: Macroeconomics 2 (2), 125-164.

Jorgenson, D., Gollop, F., Fraumeni, B.M., 1987. Productivity and US Economic Growth. Harvard University Press, Cambridge, MA.

Jorgenson, D.W., Stiroh, K.J., 2000. Raising the speed limit: US economic growth in the information age. Brookings Papers on Economic Activity 31 (1), 125-236.

Kahn, J.A., 2008. What drives housing prices? Staff Reports 345, Federal Reserve Bank of New York.

Oulton, N., 2007. Investment-specific technological change and growth accounting. Journal of Monetary Economics 54 (4), 1290-1299.

Solow, R., 1957. Technical change and the aggregate production function. The Review of Economics and Statistics 39 (3), 312-320.

\footnotetext{
9 In Fig. 1, we report data from 1987 for comparison purposes. Notwithstanding this, for the UK it is possible to construct the same figure starting in 1969. This figure confirms that the major divergence between the housing and the construction price occurs after 1995.
} 